\title{
Pengaruh Pembelajaran Pendekatan Rigorous Mathematical Thinking (RMT) terhadap Pemahaman Konseptual Matematis Siswa SMP
}

\author{
Aan Hendrayana \\ Program Studi Pendidikan Matematika Universitas Sultan Ageng Tirtayasa. Jalan Raya Jakarta Km 4, \\ Panancangan, Cipocok Jaya, Kota Serang, Banten 42124, Indonesia \\ Corresponding Author. Email: aanhendrayana@untirta.ac.id, Telp: (+62254) 280330 \\ Received: 21 August 2017; Revised: 15 December 2017; Accepted: 19 December 2017
}

\begin{abstract}
Abstrak
Penelitian ini bertujuan untuk mengkaji pengaruh pembelajaran dengan pendekatan Rigorous Mathematical Thinking (RMT) terhadap kemampuan Pemahaman Konseptual Matematis (PKM) siswa SMP yang ditinjau dari gender, Kemampuan Awal Matematika (KAM) dan Gaya Belajar Matematis (GBM) siswa. Jenis penelitian ini adalah penelitian eksperimen. Adapun penyelenggaraan pembelajaran pada penelitian ini terdiri dari: satu kelas eksperimen pria, satu kelas eksperimen wanita, satu kelas kontrol pria, dan satu kelas kontrol wanita. Kelas eksperimen diberi perlakuan pembelajaran pendekatan RMT dan kelompok kontrol diberi perlakuan pembelajaran pendekatan langsung. Hasil penelitian menunjukkan bahwa kemampuan PKM siswa pada pembelajaran pendekatan RMT lebih tinggi dari pembelajaran pendekatan langsung. Dilihat dari faktor gender, diperoleh bahwa PKM siswa wanita kelas eksperimen lebih besar secara signifikan dari kelas kontrol, akan tetapi pada kelas pria tidak berbeda secara signifikan. Dilihat dari faktor KAM, didapat bahwa PKM siswa KAM sedang dan rendah pada kelas eksperimen lebih besar secara signifikan, akan tetapi pada siswa KAM tinggi tidak berbeda secara signifikan. Adapun jika dilihat dari faktor GBM diperoleh bahwa hanya PKM siswa GBM dengan self-expressive learning yang tidak berbeda secara signifikan. Dan hasil yang penting adalah dengan pembelajaran ini menjadikan siswa dengan KAM sedang dan rendah dapat mencapai kemampuan yang baik.
\end{abstract}

Kata Kunci : Rigorous Mathematical Thinking (RMT), pemahaman konseptual matematis (PKM), gender, kemampuan awal matematika (KAM), gaya belajar matematis (GBM).

\section{The Effect of Rigorous Mathematical Thinking (RMT) Learning Approach On Students' Understanding of Mathematical Concepts}

\begin{abstract}
This study aims to examine the effect of learning with Rigorous Mathematical Thinking (RMT) approach on students's Mathematical Conceptual Understanding (PKM) of junior high school students that viewed on gender, Mathematical Preliminary Skills (KAM) and Mathematical Learning Styles (GBM). The type of this research is experimental research. The implementation of learning in this study consists of: one class of male experiments, one class of female experiments, one class of male control, and one class of female control. The experimental class was treated in a RMT approach and the control group was treated with a direct learning. The results showed that students' PKM ability on learning RMT approach is higher than direct approach learning. Viewed from the gender factor, it was found that the female students' PKM experiments were significantly greater than the control class, but in the male class did not differ significantly. Judging from KAM factors, it was found that the KAM of middle and low KAM students in the experimental class was significantly greater, but in high KAM students did not differ significantly. As if seen from the GBM factor obtained that only PKM ability in GBM students with self-expressive learning that does not differ significantly. And the important result is that this learning makes students with medium and low of KAM able to achieve good ability.
\end{abstract}

Keywords: Rigorous Mathematical Thinking (RMT), understanding of mathematical concepts (PKM), gender, initial mathematical ability (KAM), students' mathematics learning styles (GBM).

How to Cite: Hendrayana, A. (2017). Pengaruh pembelajaran pendekatan rigorous mathematical thinking (RMT) terhadap pemahaman konseptual matematis siswa SMP. Jurnal Riset Pendidikan Matematika, 4(2), 186199. doi:http://dx.doi.org/10.21831/jrpm.v4i2.15385

Permalink/DOI: http://dx.doi.org/10.21831/jrpm.v4i2.15385 


\section{PENDAHULUAN}

Kecakapan matematis adalah salah satu syarat mencapai kemajuan di zaman modern (Hudojo, 2005, p. 45; National Research Council, 2002, p. 16). Kecakapan ini merupakan bekal untuk menghadapi abad ke-21 yang serba kompetitif (Kilpatrick, Swafford, \& Findell, 2001, p. 1). Oleh karena itu, kecakapan tersebut merupakah hal yang perlu dicapai agar menjadi kompetitif dan tidak ketinggalan zaman. Pentingnya kecakapan matematis membuat bangsa-bangsa memprioritaskan matematika sebagai pelajaran utama di sekolah yang harus diperhatikan (NRC, 2002, p.4). Hanya sayang, kebanyakan siswa di sekolah sulit untuk menguasai matematika (Susilo, 2004, p. 4). Walaupun demikian, kadang kesulitan tersebut sengaja dibuat secara sengaja untuk melatih dan membiasakan siswa agar terbiasa dalam aktifitas berpikir dan aktifitas memecahkan masalah (Hudojo, 2005, p. 45; Reys, Lindquist, Lambdin, \& Smith, 2014, p. 1). Oleh sebab itu, wajar bila kecakapan matematika menjadi wahana untuk menjadikan seseorang menjadi kompetitif karena di dalamnya ada pembiasan menghadapi masalah sulit.

Untuk mencapai kecakapan matematis diperlukan lima komponen, yaitu: pemahaman konseptual (conceptual understanding), kompetensi strategis (strategic competence), kelancaran dalam prosedur pengerjaan (procedural fluency), penalaran adaptif (adaptive reasoning), dan disposisi yang produktif (productive disposition) (NRC, 2002, p.16; Kilpatrick, Swafford, dan Findell, 2001, p.1). Pemahaman konseptual, yaitu: pemahaman konsep matematika, operasinya, serta membuat hubungan antara konsep. Kelancaran dalam prosedur pengerjaan adalah kelancaran dalam melakukan operasi yang bisa dilakukan atau dengan kata lain kemampuan memecahkan masalah yang rutin. Kompetensi strategis, yaitu: kemampuan untuk merumuskan, merepresentasikan, dan memecahkan masalah matematika yang tidak rutin. Penalaran adaptif adalah bagaimana siswa dapat menilai apakah suatu pemecahan masalah benar dan masuk akal. Selanjutnya, disposisi matematis adalah sikap positif terhadap matematika. Sikap positif ini tidak lepas dari penguasaan pemahaman konseptual, kompetensi strategis, kelancaran prosedur, dan penalaran adaptif matematis yang baik sebagaimana pendapatnya Feuerstein (2017) bahwa disposisi matematika berkembang menjadi baik ketika pengelolaan domain kognitif dicapai secara baik.

Salah satu dari lima komponen kecakapan matematis yang penting untuk dicermati lebih mendalam, yaitu: Pemahaman Konseptual Matematis (PKM). Sekalipun lima komponen itu saling berkaitan erat, namun komponen PKM memiliki peran penting karena dengan kemampuan ini siswa dapat mengingat kembali suatu konsep dengan baik ketika lupa. Selanjutnya, penguasan PKM yang baik akan menjadikan siswa mudah dalam membangun hubungan untuk memahamai ide dan konsep baru (Kilpatrick et al., 2001, p. 120). Oleh karena itu, kemampuan PKM yang lemah akan menjadikan siswa menjadi bingung, frustasi, dan cemas ketika menghadapi konsep baru dari matematika. Akibat berikutnya, tidak tercapainya kemampuan ini akan menjadikan siswa menolak untuk belajar matematika karena pembelajaran tidak memberi makna pada mereka (Orton, 2004, p. 2).

Sebagai ilustrasi, ketika siswa dihadapkan dengan persoalan mencari luas jajarangenjang, kemudian mereka tidak hafal rumus mencari luasnya, maka mereka tidak akan kesulitan mencari luas jajarangenjang tersebut dikarenakan mereka paham konsep kekekalan luas (Gambar 1).

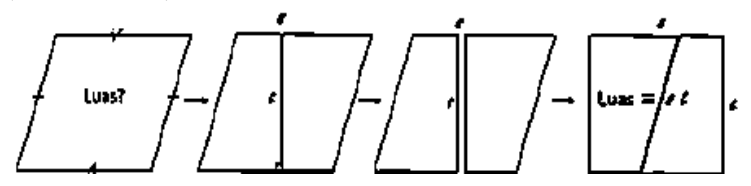

Gambar 1. Mencari Luas Jajarangenjang.

Kemampuan PKM ini dapat ditumbuhkembangkan melalui pembelajaran di kelas. Untuk mencapai kecakapan tersebut, pembelajaran perlu memperhatikan keberagaman siswa (OECD, 2010, p. 4) karena pembelajaran yang mengakomodasi keberagaman menjadi lebih efektif, efesien, dan menarik (Paas, Merrienboer, \& Gog, 2011, p. 3). Untuk itu, Pemerintah melalui UU no.2 tahun 1989 menuntut bahwa pembelajaran harus memper-hatikan keragaman siswa merupakan tuntutan dalam sistem pendidikan di Indonesia (Presiden Republik Indonesia, 1989). Tidak heran juga bila satu prinsip dari pembelajaran matematika adalah memperhatikan keberagaman siswa (National Council of Teachers of Mathematics, 2000, pp. 12-13). Keberagaman tersebut dapat berupa Gender (G), Kemampuan Awal Matematika (KAM) dan Gaya Belajar Matematis (GBM) siswa. 
Keberagaman KAM siswa dapat berkontribusi pada pemerolehan kemampuan PKM siswa. Siswa dengan KAM tinggi lebih mudah untuk mencapai kecakapan tersebut karena siswa dengan KAM ini telah mempunyai banyak skema tentang konsep matematika (Sweller, 1988). Akibatnya, mereka lebih mudah untuk mencapai kecakapan PKM. Sedangkan bagi siswa dengan KAM sedang dan rendah itu tidak mudah karena skema pembangun kecakapan dari PKM belum lengkap. Dengan kondisi ini, pembelajaran tidak hanya memberikan konsep baru tetapi juga harus dapat melengkapi prasyarat skema untuk mencapai kecakapan PKM agar dapat juga mengakomodasi siswa dengan KAM sedang dan rendah.

Keragaman GBM harus juga mendapat perhatian dari guru. Keberadaan GBM siswa ini tidak terlepas dari faktor lingkungan belajar, pendekatan pembelajaran, dan fasilitas belajar yang tersedia (Pritchard, 2013, p. 42). Faktorfaktor tersebut membentuk siswa untuk mempunyai GBM tertentu. Siswa yang biasa melakukan sesuatu secara mandiri dan sering dihadapkan pada soal problem solving (soal tidak rutin) maka mereka berpotensi mempunyai GBM Self expressive Learning (SL). Siswa yang terbiasa berkolaborasi dengan rekan berpotensi menjadi siswa yang mempunyai GBM Interpersonal Learning (IL). Siswa yang terbiasa untuk menunggu penjelasan dan prosedur pengerjaan setahap demi setahap sampai jelas berpotensi mempunyai GBM Mastery Learning (ML). Sedangkan siswa yang dibiasakan untuk bertanya dan bernalar terkait konsep yang diberikan dan biasa berhadapan dengan soal problem solving berpotensi mempunyai GBM Understanding Learning (UL). Untuk itu, aktifitas pembelajaran perlu mempertimbangkan keempat gaya belajar siswa tersebut, karena pembelajaran tidak akan menciptakan keadilan jika GBM diabaikan.

Pemahaman dan penguasan tentang kultur dan alat psikologis matematika seharusnya dapat dikuasai oleh setiap siswa yang ingin sukses dalam mencapai kecakapan matematika (Kinard \& Kozulin, 2008, p. 16; Tan, 2003, p. 205), dalam hal ini pemahaman konseptual. Pemahaman dan penguasaan yang baik terkait kultur dan alat psikologis matematika juga dapat memberikan skema untuk menata informasi yang ada pada long-term memory dan mengelolanya secara efesien di working-memory (Sweller, Ayres, \& Kalyuga, 2011, p. vii). Pendekatan pembelajaran yang memediasi siswa memahami kultur serta mendorong siswa untuk memguasai alat psikologis matematika agar terjadinya pembentukan skema tarkait matematika adalah Rigorous Mathematical Thinking (RMT). Prinsip mediasinya mengadopsi dari Feuerstien (2000), yaitu: intentionality (kesengajaan) dan reciprocity (interaksi), transcendence (menjembatani), dan meaning (memberi makna) pada setiap tahap pembelajarannya (Kinard \& Kozulin, 2008, p. 8). Dengan begitu, RMT memantau akitivitas siswa untuk siap dalam memahami dan membangun konsep serta pemecahan masalah dalam matematika.

Rangkaian pembelajaran RMT merupakan pembelajaran yang menjembatani antara pembelajaran langsung dan tidak langsung. RMT menekankan perlunya kematangan konsep dan materi prasyarat dalam pembelajaran dengan memberikan skema (Kinard \& Kozulin, 2008). Pembekalan skema memudahkan siswa dalam mengolah pengetahuan yang berakibat pada ringannya beban memori kerja (Sweller, 1994). Selain dari itu, siswa dipantau dan diarahkan selama proses pembelajaran agar siswa mencapai kecakapan dalam matematika sesuai harapan. Intensitas pemantauan dan pengarahan diturunkan secara bertahap sampai akhirnya terbentuk kemandirian dalam pemerolehan pengetahuan dan pemecahan masalah (Kinard \& Kozulin, 2008). Pada saat kemandirian dicapai maka kesulitan dalam pemerolehan pengetahuan dan pemecahan akan lebih mudah karena skema sudah menyatu dalam jiwa. Akibatnya, ketika informasi atau skema dipanggil tidak memerlukan usaha sadar dari siswa. Kondisi seperti ini disebut otomatisasi, yaitu pemanggilan informasi atau skema dari memori jangka panjang diambil secara tidak sadar (Sweller, 1994), akibatnya memori kerja tidak terbebani sehingga kinerjanya menjadi ringan dan ruangnya dapat digunakan untuk menampung informasi baru dan juga prosesnya.

Pembelajaran yang secara filosofis sama dengan RMT ini telah banyak dilakukan pada sekolah dengan karaketerisik siswa yang berkemampuan lemah dan imigran dengan kultur yang berbeda-beda (Falik, 2007). Hasil dari beberapa penelitian di luar negeri menunjukkan bahwa pemahaman dan penerapan konsep matematika siswa yang mendapat pembelajaran pendekatan RMT lebih baik dari pembelajaran pendekatan langsung (Kinard \& Kozulin, 2008). Di Indonesia, penelitian pembelajaran pendekatan RMT belum pernah ada yang melakukan baik itu di sekolah berasrama maupun bukan, 
kalaupun ada baru pada konteks pengembangan media pembelajaran seperti yang telah dilakukan oleh Khabib \& Manoy (2014). Penelitian lain yang pernah dilakukan di Indonesia adalah penelitian RMT sebagai suatu kompetensi siswa bukan sebagai rangkaian pembelajaran seperti yang telah dilakukan Fitriyani (2013) dan (Zubaidah, 2012).

Salah satu kelebihan dari pembelajaran pendekatan RMT adalah mengakomodasi keberagaman karakteristik siswa yang datang dari kultur berbeda, hal ini sesuai dengan karakteristik siswa sekolah berasrama di Indonesia. Untuk itu, penelitian ini bertujuan untuk mengkaji kemampuan PKM siswa SMP yang memperoleh pembelajaran pendekatan RMT lebih besar dari siswa yang memperoleh pembelajaran pendekatan langsung ditinjau dari: (a). Gender, (b). KAM siswa, dan (c). GBM siswa.

\section{METODE}

Jenis penelitian ini adalah penelitian eksperimen yang mengadopsi dari Fraenkel, Wallen, \& Hyun (2012, p. 249). Adapun penyelenggaraan pembelajaran pada penelitian ini terdiri dari: satu kelas eksperimen pria, satu kelas eksperimen wanita, satu kelas kontrol pria, dan satu kelas kontrol wanita. Kelas eksperimen diberi perlakuan pembelajaran pendekatan RMT (X) dan kelompok kontrol diberi perlakuan pembelajaran pendekatan langsung. Setelah perlakuan pembelajaran selesai, siswa diberi tes tertulis terkait kemampuan PKM.

Pemberian perlakuan kepada kelas eksperimen dan kontrol yang dilaksanakan selama setengah semester penuh (sembilan pertemuan ditambah dua pertemuan untuk tes kemampuan PKM). Adapun, kegiatan pembelajaran pada kelas kontrol menggunakan pendekatan langsung. Pembelajaran kelas eksperimen mengacu pada RPP dan bahan ajar (handout) yang telah disusun. Kegiatan pembelajaran pada kelas eksperimen menggunakan pendekatan RMT. Pembelajaran diakhiri dengan ujian tengah semester yang sekaligus merupakan tes untuk mengukur PKM.

Subjek dari penelitian ini adalah sekolah berasrama berbasis islam yang memiliki kelas paralel tidak lebih dari tiga kelas. Adapun, sekolah yang dijadikan sampel adalah SMP Boarding School Daarut Tauhid Kota Bandung di kelas VII. Sesuai dengan latar belakang penelitian, dipilihnya sekolah tersebut karena sekolah tersebut merupakan sekolah boarding yang diidentifikasi sebagai sekolah yang siswa- nya berasal dari beragam latar belakang kultur atau dengan kata lain berasal dari beragam daerah, dengan kriteria sekolah dan jumlah kelas seperti yang telah disebutkan.

Pemilihan subyek penelitian dilakukan sampel purposif pada siswa SMP berasrama kelas VII. Pertimbangan pemilihan kelas satu sebagai sampel karena pada level kelas ini masalah keragaman menjadi masalah pada keberlangsungan siswa di sekolah berasrama. Kondisi ini menjadi indikator penting bagi suksesnya pembelajaran pendekatan RMT sebagai pembelajaran yang mengakomodasi siswa keragaman siswa (Kinard \& Kozulin, 2008). Adapun, waktu penelitian ini dilakukan pada semester ganjil tahun pelajaran 2013/2014.

Pada penelitian ini dikembangkan tujuh buah instrumen yang terbagi dari dua kategori, yaitu tes dan non-tes. Instrumen kategori tes adalah tes Kemampuan Awal Matematika (KAM) dan tes kemampuan Pemahaman Konseptual Matematis (PKM). Adapun instrumen kategori non-tes yaitu Gaya Belajar Matematika (GBM), dan wawancara untuk siswa, guru, serta orang tua siswa.

Tes untuk mengukur KAM siswa dilakukan sebelum perlakuan pembelajaran dimulai. KAM siswa dikelompokan menjadi tiga, yaitu: siswa KAM tinggi, sedang dan tinggi. Pengelompokan KAM ditentukan dengan menggunakan pembagian mengacu pada diagram distribusi normal dengan bilangan baku $\mathrm{Z}$ (Arikunto, 1999). Siswa dengan KAM rendah berada di daerah nilai $Z \leq-1$, KAM sedang di daerah $-1<$ $\mathrm{Z}<1$, dan $\mathrm{KAM}$ tinggi di daerah $\mathrm{Z} \geq 1$. Adapun soal yang dijadikan untuk menguji KAM siswa adalah soal ujian tengah semester yang dimodifikasi oleh guru setiap tahunnya dengan standar yang telah ditetapkan oleh Dinas Pendidikan Kota Bandung. Keyakinan pengelompokan KAM siswa tidak hanya terbatas pada tes namun juga pada observasi selama setengah semester dan wawancara dengan rekan siswa dan guru.

Adapun instrumen tes PKM digunakan pada saat ujian tengah semester yang sekaligus merupakan tes untuk mengukur PKM. Indikator dari PKM siswa, yaitu: kemampuan untuk memahami konsep matematika, mengoperasikan konsep matematika dan mengkaitkan konsep matematika. Setiap kemampuan pada PKM siswa mengikuti kompetensi dasar yang dipersyaratkan Kementerian Pendidikan dan Kebudayaan (KEMDIKBUD). Kemudian, soal yang diberikan dalam bentuk isian dengan 
tujuan untuk mengetahui jejak kerja siswa dalam menyelesaikan persoalan yang diberikan.

Kegiatan untuk mengetahui validitas logis dari instrumen yang akan digunakan dilakukan melalui konsultasi dengan pakar Pendidikan Matematika dari Universitas Pendidikan Indonesia (UPI). Selanjutnya, Validitas Konstruksi digunakan untuk mengukur setiap aspek dari PKM. Untuk tujuan uji tersebut, instrumen diperiksa oleh tiga dosen Pendidikan Matematika Universitas Sultan Ageng Tirtayasa agar memvalidasi dan mengkoreksi kebenaran dan kesesuaian PKM siswa SMP. Penghitungan reliabilitas hasil dari uji coba instrumen PKM didapat $r_{11}=0,70$ dan $r_{\text {tabel }}=0,355$ dengan taraf signifikasi 5\%. Dari nilai $r_{11}$ dan $r_{\text {tabel }}$ didapat $r_{11}$ $>r_{\text {tabel}}$, disimpulkan soal instrumen adalah reliabel dengan katagori sedang. Instrumen untuk melihat GBM siswa pada penelitian ini menggunakan instrumen dari Strong, Thomas, Perini, \& Silver (2004). Instrumen ini terdiri dari 40 pertanyaan yang masing-masing gaya belajar mempunyai 10 pertanyaan dan skor setiap pertanyaan maskimal 2 dan skor minimal 0 . Realibilitas intrumen telah diuji Abrams (2013).

Adapun instrumen GBM yang diambil dari Strong et al. (2004) dan di uraikan oleh Golden (2010) dalam bentuk kuesioner berbahasa Inggris. Instrumen GBM dialih-bahasakan ke bahasa Indonesia. Setelah dialih-bahasa, instrumen dikoreksi salah satu dosen Pendidikan Bahasa Inggris Universitas Sultan Ageng Tirtayasa.

Wawancara ini dilakukan ketika sebelum perlakuan dan saat pembelajaran. Wawancara sebelum perlakuan pembelajaran dilakukan untuk mengetahui pendapat siswa terhadap pembelajaran dengan pendekatan RMT. Adapun wawancara setelah pembelajaran dilakukan untuk mengetahui apa yang terjadi dengan pekerjaan yang hasilkan. Wawancara tidak dilakukan untuk semua siswa, akan tetapi dipilih berdasarkan fenomena yang muncul untuk mencari penjelasan dari fenomena tersebut.

Observasi dilakukan sebelum diberikan perlakuan dan saat pembelajaran. Observasi sebelum pembelajaran dilakukan untuk memastikan apakah pengelompokan KAM dan GBM dilakukan secara benar. Adapun, observasi saat pembelajaran dilakukan untuk melihat perilaku belajar siswa. Kedua observasi ini kebanyakan menggunakan video untuk kebutuhan pengulangan pengamatan.

Pengumpulan data pada penelitian ini terdiri dari empat, yaitu: evaluasi tes, obervasi, wawancara, dan dokumentasi. Keempat data tersebut saling tekait satu sama lain. Maksud saling terkait adalah data tes disandingkan dengan observasi kemudian diklarifikasi melalui wawancara yang kemudian dibuktikan dengan dekumentasi berupa hasil kerja (portofolio).

\section{HASIL DAN PEMBAHASAN}

Penelitian ini melibatkan 51 siswa dan 53 siswi SMP. Berikut merupakan tabulasi gender dan KAM yang disajikan dalam Tabel 1.

Tabel 1. Tabulasi KAM dan Gender

\begin{tabular}{|c|c|c|c|c|c|}
\hline \multirow{2}{*}{ КАМ } & \multicolumn{4}{|c|}{ Kelas } & \multirow{2}{*}{ Total } \\
\hline & EP & EW & $\mathbf{K P}$ & $\mathbf{K W}$ & \\
\hline Tinggi & 4 & 4 & 3 & 4 & 15 \\
\hline Sedang & 19 & 19 & 14 & 18 & 70 \\
\hline Rendah & 5 & 4 & 6 & 3 & 18 \\
\hline Total & 28 & 27 & 23 & 25 & 103 \\
\hline
\end{tabular}

Keterangan: EP $=$ Kelas eksperimen siswa laki-laki, EW = Kelas eksperimen siswa perempuan, $\mathrm{KP}=$ Kelas kontrol siswa laki-laki, $\mathrm{KW}=$ Kelas kontrol siswa perempuan.

Berdasarkan Tabel 1 diperoleh KAM siswa SMP tersebut pada setiap kelasnya di kelas satu terdistribusi secara baik. KAMsedang selalu lebih banyak kemudian KAM rendah dan tinggi hampir sebanding. Ini terjadi karena pihak sekolah mempertimbangkan kemampuan siswa secara terdistribusi ketika penempatan kelas. Kesimpulan ini merupakan hasil wawancara dengan ketua panitia penerimaan siswa baru.

Adapun terkait identifikasi GBM siswa dilakukan melalui pengisian kuesioner kemudian dikonfirmasi melalui wawancara dan observasi. Wawancara dilakukan pada siswa ketika tidak didapat kesimpulan yang pasti tentang GBM mereka. Berikut merupakan tabulasi gender dan GBM yang disajikan dalam Tabel 2.

Tabel 2. Tabulasi GBM dan Gender

\begin{tabular}{|c|c|c|c|c|c|}
\hline \multirow{2}{*}{ КАМ } & \multicolumn{4}{|c|}{ Kelas } & \multirow{2}{*}{ Total } \\
\hline & EP & EW & KP & $\mathbf{K W}$ & \\
\hline $\begin{array}{l}\text { Mastery Learning } \\
\text { (ML) }\end{array}$ & 8 & 11 & 6 & 10 & 35 \\
\hline $\begin{array}{l}\text { Interpersonal } \\
\text { Leaning (IL) }\end{array}$ & 11 & 4 & 6 & 5 & 26 \\
\hline $\begin{array}{l}\text { Understanding } \\
\text { Learning (UL) }\end{array}$ & 4 & 4 & 5 & 5 & 18 \\
\hline $\begin{array}{l}\text { Self-expressive } \\
\text { Learning (SL) }\end{array}$ & 5 & 8 & 6 & 5 & 24 \\
\hline Total & 28 & 27 & 23 & 25 & 103 \\
\hline
\end{tabular}

Keterangan: $\mathrm{EP}=$ Kelas eksperimen siswa laki-laki, $\mathrm{EW}=$ Kelas eksperimen siswa perempuan, KP = Kelas kontrol siswa laki-laki, $\mathrm{KW}=$ Kelas kontrol siswa perempuan. 


\section{Perbandingan PKM Kelas Eksperimen dan Kontrol}

Untuk menguji hipotesis penelitian yang menyatakan bahwa PKM siswa kelas eksperimen lebih besar dari kelas kontrol maka secara formal hipotesis statistik (H0) dan hipotesis penelitian (H1) adalah sebagai berikut:

$\mathrm{H}_{0}$ : Tidak ada perbedaan PKM siswa antara kelompok eksperimen dan kontrol

$\mathrm{H}_{1}$ : Ada perbedaan PKM siswa kelas eksperimen lebih besar dari kelas kontrol.

Secara statistik, hipotesis tersebut dapat disimbolkan sebagai berikut.

$\mathrm{H}_{0}: \mu_{\mathrm{E}}-\mu_{\mathrm{K}}=0$

$\mathrm{H}_{1}: \mu_{\mathrm{E}}-\mu_{\mathrm{K}} \neq 0$

Kriteria pengujian terima $\mathrm{H}_{0}$ ketika $\mathrm{t}_{\text {kritis }} \geq$ $t_{\text {hitung }}$ atau $p$-value $\geq 0,025$. Tabel 3 memperlihatkan beberapa ukuran yang dapat membandingan kelas eksperimen dengan kontrol. Ukuran tersebut dapat dikelompokkan menjadi dua bagian yaitu data pemusatan dan penyebaran.

Tabel 3. Statistik Deskriptif PKM Kelas Eksperimen dan Kontrol

\begin{tabular}{lcc}
\hline \multirow{2}{*}{ Statistik } & \multicolumn{2}{c}{ PKM } \\
\cline { 2 - 3 } & $\begin{array}{c}\text { Kelas } \\
\text { Eksperimen }\end{array}$ & $\begin{array}{c}\text { Kelas } \\
\text { Kontrol }\end{array}$ \\
\hline Mean & 9.62 & 6.69 \\
Median & 10.00 & 7.00 \\
Standar Deviasi & 3.34 & 3.74 \\
Minimum & 2 & 0 \\
Maksimum & 15 & 15 \\
Kurtosis & $-0,347$ & $-0,585$ \\
\hline
\end{tabular}

Berdasarkan Tabel 3, data pemusatan kelas eksperimen lebih berada di atas kelas kontrol. Denikian pula data penyebaran kelas eksperimen lebih kecil dari kelas kontrol. Selain dari itu, skor kurtosis pada kelas eksperimen lebih dekat ke nol dibanding kelas kontrol menunjukan bahwa bentuk sebaran data kelas eksperimen dekat dengan rataannya dibanding kelas kontrol. Oleh karena itu, dugaan yang kuat bahwa PKM siswa kelas eksperimen lebih besar dari kelas kontrol. Namun untuk menguatkan kesimpulan diperlukan uji statistika inferensial. Uji statistika inferensi diawali dengan uji asumsi, yaitu: normalitas dan kehomogenan data.

Hasil uji normalitas menggunakan uji Kolmogorov-Smirnov menghasikan kesimpulan bahwa data kelas eksperimen dan kontrol berdistribusi normal. Kesimpulan tersebut didapatkan setelah melihat nilai $p$-value dari 0,05.
Uji berikutnya adalah uji kehomogenan data yang menggunakan uji levene. Hasil ujinya adalah dua data yang dibandingkan homogen karena $p$-value $=0,334$ lebih dari 0,05. Setelah dilakukan uji asumsi, uji berikutnya adalah uji beda. Oleh karena itu, diperoleh bahwa data berdistribusi normal dan homogen. Dengan demikian data akan diuji menggunakan uji t.

Hasil uji-t menghasilkan $p$-value $=0,000$ dengan $\mathrm{t}_{\text {hitung }}=4,199$. Untuk mengetahui bahwa hipotesis statistik ditolak atau diterima maka harus membandingkan $t_{\text {hitung }}$ dengan $t_{\text {kritis. }}$. Setelah melihat tabel $t$ didapatkan $t_{\text {kritis }}=1,96$, ini artinya $t_{\text {hitung }}>t_{\text {kritis. }}$. Dengan $t_{\text {hitung }}>t_{\text {kritis }}$ maka $\mathrm{H}_{0}$ ditolak. Penolakan $\mathrm{H} 0$ diperkuat dengan $p$-value kurang dari 0,025. Dapat disimpulkan bahwa PKM siswa pada kelas eksperimen lebih besar dari kelas kontrol.

Ini memberikan bukti bahwa pembelajaran pendekatan RMT mempunyai pengaruh yang lebih baik terhadap kemampuan PKM dibanding pembelajaran pendekatan langsung karena kekuatan pemanfaatan alat psikologisnya (Kinard \& Kozulin, 2008, p. 11). Hal seperti sejalan dengan pendapatnya Vygotsky (1978) yang menyatakan bahwa alat psikologis yang dapat membuat siswa mudah dalam memahami dan mengaitkan suatu konsep.

Selain itu, pembelajaran pendekatan RMT telah membiasakan siswa untuk membangun konsep dengan memahami kultur matematika. Kemudian, guru yang bertidak sebagai MLE berperan aktif untuk mengontrol, meluruskan dan memberikan bantuan berupa scaffolding dengan alat psikologis sebagai alat dalam memahami, mengitegrasikan, dan mengembangkan konsep matematik. Aktifitas guru sebagai MLE telah membuahkan hasil yang bagus, kondisi ini sejalan dengan pendapatnya Feuerstein (2000) yang menyatakan bahwa peran guru sebagai mediator akan menjadikan siswa mendapat kompetensi yang lebih unggul. Selanjutnya, penggunaan alat psikologis adalah scaffolding membuat siswa mudah untuk menerima konsep baru kemudian mengoperasikan konsep dan mengkaitkan konsep baru dengan konsep lain secara lebih mudah.

\section{Perbandingan PKM Kelas Eksperimen dan Kontrol, Ditinjau dari Gender}

Untuk menguji hipotesis penelitian yang menyatakan bahwa PKM siswa kelas eksperimen lebih besar dari kelas kontrol, ditinjau dari gender, maka secara formal hipotesis statistik 
$\left(\mathrm{H}_{0}\right)$ dan hipotesis penelitian $\left(\mathrm{H}_{1}\right)$ adalah sebagai berikut:

$\mathrm{H}_{0}$ : Tidak ada perbedaan PKM siswa antara kelompok eksperimen dan kontrol, ditinjau dari kelas gender

$\mathrm{H}_{1}$ : Ada perbedaan PKM siswa antara kelompok eksperimen dan kontrol, ditinjau dari kelas gender

Secara statistik, hipotesis tersebut dapat disimbolkan sebagai berikut.

$\mathrm{H}_{0}: \mu_{\mathrm{A}}-\mu_{\mathrm{B}}=0, \mathrm{~A} \neq \mathrm{B}$ dimana $\mathrm{A}, \mathrm{B}=\{\mathrm{EP}, \mathrm{EW}$, $\mathrm{KP}, \mathrm{KW}$.

$\mathrm{H}_{1}:$ 目 $\mu_{\mathrm{A}}-\mu_{\mathrm{B}} \neq 0, \mathrm{~A} \neq \mathrm{B} \operatorname{dimana} \mathrm{A}, \mathrm{B}=\{\mathrm{EP}, \mathrm{EW}$, $\mathrm{KP}, \mathrm{KW}$.

Kriteria pengujian terima $\mathrm{H}_{0}$ ketika $p$ value $>0,05$. Tabel 4 memperlihatkan beberapa ukuran yang dapat membandingan kelas eksperimen dengan kontrol.

Tabel 4. Statistik Deskriptif PKM Kelas Eksperimen dan Kontrol Ditinjau dari Gender

\begin{tabular}{lcccc}
\hline \multirow{2}{*}{ Statistik } & \multicolumn{4}{c}{ Kelas } \\
\cline { 2 - 5 } & EP & EW & KP & KW \\
\hline Mean & 9.68 & 9.56 & 7.09 & 6.32 \\
Median & 10.00 & 10.00 & 6.00 & 7.00 \\
Standar Deviasi & 3.611 & 3.105 & 4.522 & 2.897 \\
Minimum & 2 & 3 & 0 & 0 \\
Maksimum & 15 & 15 & 15 & 12 \\
Kurtosis & -0.229 & -0.428 & -1.192 & -0.279 \\
\hline
\end{tabular}

Dari pertimbangan Tabel 4 tersebut, potensi PKM siswa kelas eksperimen pria maupun wanita lebih besar dari kelas kontrol diduga kuat dapat terjadi. Walaupun demikian, potensi ini harus diyakinkan dengan pengujian statistika inferensi. Pengujian statistika inferensial membutuhkan uji asumsi normalitas dan kehomogenan data. Hasil uji normalitas menggunakan uji Kolmogorov-Smirnov mensimpulkan bahwa data kelas eksperimen dan kontrol berdistribusi normal. Simpulan tersebut didapatkan setelah melihat semua $p$-value lebih dari 0,05 . Hasil uji kehomogenan data dari dua kelompok data menghasilkan simpulan bahwa data yang dibandingkan tidak homogen, simpulan tersebut didapatkan setelah melihat semua $p$-value kurang dari 0,05 . Setelah melakukan uji asumsi didapatkan alat uji statistika inferensial adalah ANOVA satu jalur.

Hasil uji ANOVA, p-value kurang dari 0,05 yang menunjukan bahwa minimal ada dua rerata yang berbeda. Walapun demikian, perbedaan itu tidak ditentukan oleh perbedaan perlakuan atas gender siswa melainkan karena perbedaan pada kelompoknya, hal tersebut ditandai jumlah kuadrat dari within groups (dalam kelompok) lebih besar Between Groups (antar kelompok).

Tabel 5. Uji ANOVA PKM Kelas Eksperimen dan Kontrol, Ditinjau dari Gender

\begin{tabular}{llllll}
\hline & $\begin{array}{c}\text { Jumlah } \\
\text { Kuadrat }\end{array}$ & $\begin{array}{c}\text { Derajat } \\
\text { kebebasan }\end{array}$ & $\begin{array}{c}\text { Kuadrat } \\
\text { tengah }\end{array}$ & $\begin{array}{c}\text { F } \\
\text { hitung }\end{array}$ & Sig. \\
\hline $\begin{array}{l}\text { Between } \\
\text { Groups }\end{array}$ & 227.397 & 3 & 75.799 & 5.984 & .001 \\
Within & 1254.040 & 99 & 12.667 & & \\
Groups & & & & & \\
Total & 1481.437 & 102 & & & \\
\hline
\end{tabular}

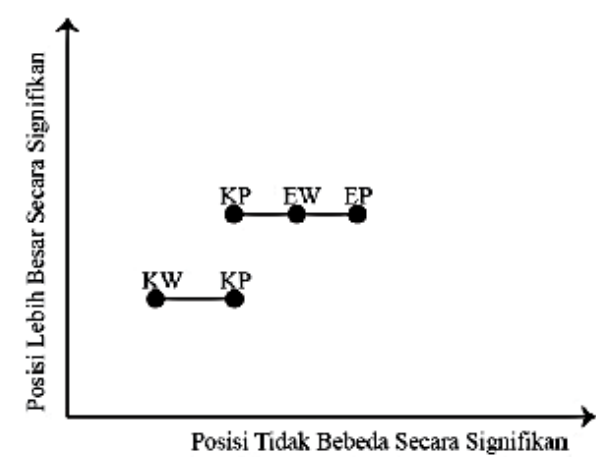

Gambar 2. Diagram Post Hoc PKM Kelas Eksperimen dan Kontrol, Ditinjau dari Gender

Uji lanjutan diperlukan untuk mengetahui kelompok data mana yang lebih besar. Pada uji lanjutan ini digunakan Games-Howell karena kelompok data yang dibandingkan tidak homogen. Hasil uji lanjutan diperlihatkan pada Gambar 2. Simpulan dari gambar tersebut yaitu: PKM siswa EP dengan KP tidak terdapat perbedaan secara signifikan dan PKM siswa EW lebih besar dari KW secara signifikan. Dari dua simpulan tersebut, temuan yang tidak sesuai hipotesis penelitian adalah PKM siswa EP dengan KP tidak terdapat perbedaan secara signifikan.

Berdasarkan hasil tersebut, RMT sebagai bentuk dari inovasi pembelajaran telah membuktikan tidak identik untuk kelompok gender tertentu (Kinard \& Kozulin, 2008). Begitu juga aktifitas MLE pada RMT telah memfasilitasi pada semua gender siswa sehingga tidak ada gap yang signifikan antara pria dan wanita. Kondisi terebut sesuai dengan prinsip equity dari National Council of Teachers of Mathematics (2000, p. 11) bahwa pembelajaran hendaknya memberikan kesempatan yang sama pada kelompok siswa. Anggapan yang menyatakan matematik lebih cocok pada gender pria (Guiso, Monte, Sapienza, \& Zingales, 2008) itu tidak terjadi pada RMT. Selanjutnya, fakta PKM siswa EP, EW, dan KP tidak berbeda secara 
signfiikan serta EP dan EW lebih besar secara signifikan dari KW memperlihatkan bahwa RMT telah memberikan kesempatan siswa wanita untuk mencapai kemampuan dalam matematika menjadi lebih baik.

Faktor pemberian kerangka sesuai skema siswa dan aktifitas pematauan yang aktif dari siswa menjadikan siswa wanita yang cenderung tertutup menjadi lebih terakses (OECD, 2010, p. 137). Hal ini sejalan dengan Fennema (1996) yang menyatakan bahwa pemilihan pembelajaran yang sesuai dapat menghilangkan gap kemampuan antara pria dan wanita.

\section{Perbandingan PKM Kelas Eksperimen dan Kontrol, Ditinjau dari KAM}

Untuk menguji hipotesis penelitian yang menyatakan bahwa PKM siswa kelas eksperimen lebih besar dari kelas kontrol, ditinjau dari KAM, maka secara formal hipotesis statistik $\left(\mathrm{H}_{0}\right)$ dan hipotesis penelitian $\left(\mathrm{H}_{1}\right)$ adalah sebagai berikut:

$\mathrm{H}_{0}$ : Tidak ada perbedaan PKM siswa antara kelompok eksperimen dan kontrol, ditinjau dari KAM

$\mathrm{H}_{1}$ : Ada perbedaan PKM siswa antara kelompok eksperimen dan kontrol, ditinjau dari KAM

Secara statistik, hipotesis di atas dapat disimbolkan sebagai berikut.

$\mathrm{H}_{0}: \mu_{\mathrm{A}}-\mu_{\mathrm{B}}=0, \mathrm{~A} \neq \mathrm{B}$ dimana $\mathrm{A}, \mathrm{B}=\{\mathrm{TE}, \mathrm{TK}, \mathrm{SE}$, SK, RE, RK\}.

$\mathrm{H}_{1}$ : $\mathrm{B} \mu_{\mathrm{A}}-\mu_{\mathrm{B}} \neq 0, \mathrm{~A} \neq \mathrm{B}$. dimana $\mathrm{A}, \mathrm{B}=\{\mathrm{TE}, \mathrm{TK}$, SE, SK, RE, RK\}.

Kriteria pengujian terima $\mathrm{H} 0$ ketika $p$ value $>0,05$. Tabel 6 memperlihatkan beberapa ukuran yang dapat membandingan kelas eksperimen dengan kontrol.

Tabel 6. Statistik Deskriptif PKM Kelas Eksperimen dan Kontrol Ditinjau dari KAM

\begin{tabular}{lcccccc}
\hline \multirow{2}{*}{ Statistik } & \multicolumn{2}{c}{ KAM } & \multicolumn{2}{c}{ KAM } & \multicolumn{2}{c}{ KAM } \\
& \multicolumn{2}{c}{ Tinggi (T) } & \multicolumn{2}{c}{ Sedang (S) } & \multicolumn{2}{c}{ Rendah (R) } \\
\cline { 2 - 7 } & E & K & E & K & E & K \\
\hline Mean & 13.2 & 9.63 & 8.86 & 6.51 & 9.11 & 2.45 \\
Median & 14 & 9 & 9 & 7 & 10 & 2 \\
Standar & 2.29 & 3.82 & 2.80 & 3.23 & 4.17 & 1.98 \\
Deviasi & & & & & & \\
Minimum & 9 & 4 & 2 & 1 & 2 & 0 \\
Maksimum & 15 & 15 & 14 & 13 & 14 & 5 \\
Kurtosis & .054 & - & - & - & - & - \\
& & 1.13 & .117 & .841 & .198 & 1.55 \\
\hline
\end{tabular}

Keterangan: $\mathrm{E}=$ Kelas eksperimen, $\mathrm{K}=$ Kelas kontrol.

Fakta pengumpulan dan penyebaran pada statistika deskriptif memperlihatkan potensi bahwa PKM siswa kelompok data kelas eksperimen lebih besar dari kelas kontrol, namun keyakinan ini memerlukan uji statistika inferensi untuk melihat keberartiannya (signifikasi). Uji statistika inferensi memerlukan uji asumsi yaitu normalitas dan kehomogenan data. Hasil uji normalitas menggunakan uji KolmogorovSmirnov data kelas eksperimen dan kontrol berdistribusi normal. Uji kehomogenan data antar kelompok data mensimpulkan bahwa kelompok data yang dibandingkan homogen karena $p$-value lebih dari 0,05. Uji ANOVA dilakukan karena hasil uji asumsi mensimpulkan bahwa data berdistribusi normal.

Tabel 7. Uji ANOVA PKM Kelas Eksperimen dan Kontrol, Ditinjau dari KAM

\begin{tabular}{llllll}
\hline & $\begin{array}{c}\text { Jumlah } \\
\text { Kuadrat }\end{array}$ & $\begin{array}{c}\text { Derajat } \\
\text { kebebasan }\end{array}$ & $\begin{array}{c}\text { Kuadrat } \\
\text { tengah }\end{array}$ & $\begin{array}{c}\text { F } \\
\text { hitung }\end{array}$ & Sig. \\
\hline $\begin{array}{l}\text { Between } \\
\text { Groups }\end{array}$ & 624.857 & 5 & 124.971 & 14.152 & .000 \\
$\begin{array}{l}\text { Within } \\
\text { Groups }\end{array}$ & 856.580 & 97 & 8.831 & & \\
Total & 1481.437 & 102 & & & \\
\hline
\end{tabular}

Hasil uji ANOVA, p-value kurang dari 0,05 menunjukan bahwa minimal ada dua rerata yang berbeda. Perbedaan tersebut tidak ditentukan oleh perbedaan perlakuan atas KAM siswa melainkan karena perbedaan pada kelompoknya, hal itu ditandai jumlah kuadrat dari within groups (dalam kelompok) lebih besar Between Groups (antar kelompok).

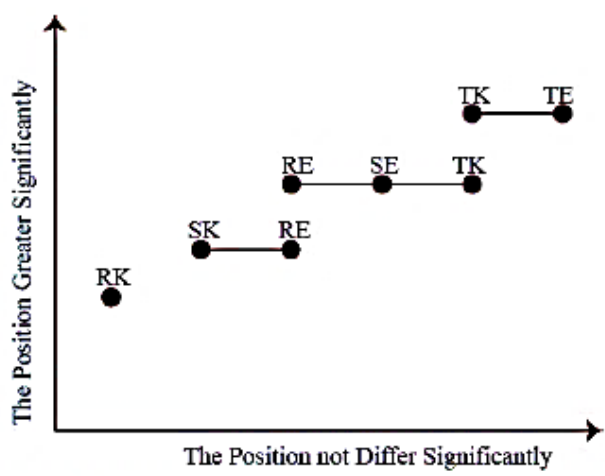

Gambar 3. Diagram Post Hoc PKM Kelas Eksperimen dan Kontrol, Ditinjau dari KAM

Hasil uji post hoc (lanjutan) diperlihatkan pada Gambar 3. Simpulan dari gambar tersebut yaitu: (1) PKM siswa TE dengan TK tidak terdapat perbedaan secara signifikan, (2) PKM siswa SE lebih besar dari SK secara signifikan, dan (3) PKM siswa RE lebih besar dari RK secara signifikan. Dari tiga simpulan tersebut, temuan yang tidak sesuai hipotesis penelitian 
adalah PKM siswa TE dengan TK tidak terdapat perbedaan secara signifikan.

Pengaruh pembelajaran terhadap KAM siswa menghasilkan beberapa temuan. Temuan pertama, perbedaan PKM siswa bukan karena adanya pengelompokan siswa berdasar KAM. Hal ini memberikan gambaran bahwa perlakuan pembelajaran sudah berlaku adil terhadap siswa dilihat dari sisi KAM. Kondisi ini menjadi kabar baik bagi RMT karena National Council of Teachers of Mathematics (2000) mengajurkan pembelajaran matematika di kelas harus menciptakan rasa berkeadilan, dalam hal ini KAM. Kedua, PKM siswa TE dan TK tidak berbeda secara signifikan. Tidak berbedanya siswa TE dan TK tidak lepas dari matangnya skema prasyarat siswa KAM tinggi, sedangkan kematangan skema mereka akan menjadi penentu skema baru (Schoenfeld, 1983; Sweller, 1988). Hal ini sejalan dengan temuan Isnarto, Wahyudin, Suryadi, \& Dahlan (2014; Pujiastuti, Kusumah, Sumarmo, \& Dahlan (2014; Sari, Nurochmah, Haryadi, \& Syaiturjim (2016); Samparadja, Suryadi, \& Kartasasmita (2014); Syamsuri, Purwanto, Subanji, \& Irawati (2016) yang menyatakan bahwa KAM menjadi satu faktor yang berpengaruh pada pencapaian kemampuan siswa.

Sekalipun begitu, tidak berbedanya PKM TE dan TK tidak berarti bahwa itu dianggap sama persis. Bila dicermati pada uji lanjutan bahwa TE sebenarnya lebih besar, hanya saja tidak signifikan. Pencermatan tersebut sesuai dengan temuan pada hasil kerja siswa KAM TE dan TK. Nampak bahwa terdapat kesalahan pada salah satu siswa TK yang fatal dan itu tidak terdapat pada siswa TK. Kesalahan tersebut adalah masalah koefisien negatif pada suatu variabel dari bentuk pertidaksamaan. Fakta ini akan menjadi masalah ketika model soal pilihan ganda karena model soal tersebut lebih pada penilaian hasil daripada proses. Fakta ini juga menegaskan bahwa pendekatan RMT tetap mampu mengakomodasi kemampuan siswa KAM tinggi yang mempunyai potensi tinggi untuk mencapai kompetensi yang lebih baik dari rekan lain. Jadi, PKM yang bagus bukan hanya faktor kelengkapan skema sebelumnya saja tetapi juga bagaimana efektifnya pembentukan skema pada pembelajaran saat itu.

Ketiga, PKM siswa SE lebih besar secara signifikan dari siswa SK. Temuan bahwa PKM Siswa SE lebih besar secara signifikan daripada SK dan tidak berbeda secara signifikan bahwa RMT telah memberikan pengaruh yang baik pada siswa SE. Siswa SE dengan skema prasyarat yang sama dengan SK ternyata besar secara signifikan memperlihatkan keunggulan RMT. Pencapaian PKM yang bagus dari SE diduga kuat karena pengaruh pendekatan RMT yang telah menambah skema prayarat dan menatanya dengan skema baru. Aktifitas penambahan skema dilakukan pada saat pada awal pembelajaran di bagian apersepsi dipatau selama pembelajaran dengan mediasi, serta ditekankan di bagian penyimpulan. Aktifitas pembekalan skema pada apersepsi membuat siswa dapat mengaitkan konsep yang telah dipelajari dengan konsep yang akan dipelajari, pada apersepsi ini siswa akan tersadarkan bahwa matematika memiliki sifat struktural dan sistemik yang membentuk suatu hirarki saling bergantung, dimulai dengan konsep yang paling inti dan berkembang pada ide matematika besar (Kinard \& Kozulin, 2008, p. 3). Aktifitas mediasi aktif dari guru selama proses pembelajaran memberikan guru untuk memberikan scafolding selama pembelajaran, peran scaffolding berupa alat psikologis membuat mereka lebih mudah mencapai kemampuan dalam PKM. Di akhir, aktifitas penyimpulan adalah aktifitas pelurusan simpulan siswa selama mengkonstuksi dan mengintegrasikan konsep.

Keempat, PKM siswa RE lebih besar secara signifikan dari siswa RK. Temuan bahwa PKM Siswa RE lebih besar secara signifikan daripada RK dan bahkan tidak berbeda secara signifikan dengan SK menggambarkan bahwa RMT juga telah memberikan pengaruh yang baik pada siswa KAM rendah. Siswa RE yang cenderung mempunyai materi prasyarat kurang ternyata dapat mencapai PKM yang baik padahal pada banyak temuan penelitian bahwa KAM menjadi faktor penentu dalam mencapai hasil belajar yang baik, dalam hal ini PKM. Diduga kuat bahwa baiknya PKM RE karena aktifitas mediasi yang intensif dari guru sehingga kekurangan skema dan ketidak-cakapan dalam menghadapi persoalan matematika dapat diselesaikan dengan guru. Feuerstein (1997) berpendapat bahwa ada harapan tinggi pada siswa bekemampuan rendah asal mediator dapat memahami Structure Cognitif Modifability (SCM) siswa berkemampuan rendah. Sekalipun pengaruh RMT terhadap siswa RE cukup baik dibanding pembelajaran pendekatan langsung, namun RMT masih meninggalkan beberapa masalah. Bila mencermati hasil kerja RE, kebanyakan hasil kerja RE belum tuntas pada pemahaman konsep dan pengoperasian konsep. 
Pada pengaitan konsep bentuk aljabar terhadap persamaan maupun pertidaksamaan belum tercapai dengan baik. Pada proses pengerjaan soal, RE cukup puas telah dapat menyelesaikan soal pemahaman dan pengoperasian. Bagi mereka, soal pengaitan konsep adalah kemampuan yang cukup rumit dan terlalu tinggi. Ini artinya untuk persoalan konsep untuk siswa SE tidak masalah karena pembelajaran pendekatan RMT dapat mengatasinya dengan bantuan alat psikologis dan aktifitas mediasi aktifnya. Menurut Sweller (1988) kesalahan konsep kerap terjadi pada siswa kemampuan rendah pada pembelajaran tidak langsung yang cenderung mendapatkan bimbingan yang minimal dari guru.

Dari penjelasan dan temuan penelitian bahwa kemampuan PKM siswa SE dan RE lebih besar dari pasangan KAM di kelas kontrol memperlihatkan bahwa optimisme Feuerstein (2003) dengan SCM-nya yang menyatakan bahwa semua siswa dapat cerdas asal mediasi dilakukan secara baik terbukti di sini. Tentu saja, optimisme guru berada pada daerah Zone Proximal Development (ZPD) siswa, yaitu wilayah kemampuan yang potensial dapat dicapai oleh siswa (Vygotsky, 1978). Oleh karena itu, ZPD pada pembelajaran dapat diakses dengan baik oleh siswa sangat ditentukan oleh peran mediator di kelas melalui penataan skema dan scaffolding alat psikologis dalam kontek kultur matematika, sementara itu aktifitas mediasi menjadi faktor penentu kepercayaan diri siswa untuk mencapai kemampuan PKM (Hassaskhah, 2012). Sehingga kemudian, pencapaian kemampuan berbeda pada KAM tinggi dengan rendah dan sedang merupakan suatu hal yang dianggap wajar karena siswa KAM tinggi sudah terbiasa menghadapi konsep matematika dan pengembangannya sehingga mudah untuk mencerna dan menyelesaikan sedangkan siswa KAM sedang dan rendah belum terbiasa (Sweller, 1994).

\section{Perbandingan PKM Kelas Eksperimen dan Kontrol, Ditinjau dari GBM}

Untuk mengetahui apakah PKM siswa kelas eksperimen lebih besar dari kelas kontrol, ditinjau dari GBM, maka secara formal dapat dinyatakan dalam bentuk hipotesis statistik $\left(\mathrm{H}_{0}\right)$ dan hipotesis penelitian $\left(\mathrm{H}_{1}\right)$ adalah sebagai berikut:

$\mathrm{H}_{0}$ : Tidak ada perbedaan PKM siswa antara kelompok eksperimen dan kontrol, ditinjau dari KAM

$\mathrm{H}_{1}$ : Ada perbedaan PKM siswa antara kelompok eksperimen dan kontrol, ditinjau dari KAM

Secara statistik, hipotesis di atas dapat disimbolkan sebagai berikut.

$\mathrm{H}_{0}: \mu_{\mathrm{A}}-\mu_{\mathrm{B}}=0, \mathrm{~A} \neq \mathrm{B}$ dimana $\mathrm{A}, \mathrm{B}=\{\mathrm{MLE}, \mathrm{ILE}$, ULE, SLE, MLK, ILK, ULK, SLK\}.

$\mathrm{H}_{1}:$ 目 $\mu_{\mathrm{A}}-\mu_{\mathrm{B}} \neq 0, \mathrm{~A} \neq \mathrm{B}$ dimana $\mathrm{A}, \mathrm{B}=\{\mathrm{MLE}$,

ILE, ULE, SLE, MLK, ILK, ULK, SLK $\}$.

Kriteria pengujian terima $\mathrm{H}_{0}$ ketika $p$ value $>0,05$. Tabel 8 memperlihatkan beberapa ukuran yang dapat membandingan kelas eksperimen dengan kontrol.

Langkah menuju statistika inferensi adalah uji normalitas dan uji kehomogenan data. Hasil uji normalitas menggunakan menurut uji Shapiro-Wilk bahwa data berdistribusi normal. Uji kehomogenan data antar kelompok data diperlukan untuk kebutuhan uji lanjutan. Dari uji ini, kelompok data yang dibandingkan homogen karena pvalue lebih dari 0,05. Uji ANOVA menjadi pilihan setelah dilakukan uji asumsi.

Tabel 8. Statistik Deskriptif PKM Kelas Eksperimen dan Kontrol Ditinjau dari GBM

\begin{tabular}{lccccccccc}
\hline \multirow{2}{*}{ Statistik } & \multicolumn{2}{c}{ ML } & \multicolumn{2}{c}{ IL } & \multicolumn{2}{c}{ UL } & \multicolumn{2}{c}{ SL } \\
\cline { 2 - 10 } & $\mathbf{E}$ & $\mathbf{K}$ & $\mathbf{E}$ & $\mathbf{K}$ & $\mathbf{E}$ & $\mathbf{K}$ & $\mathbf{E}$ & $\mathbf{K}$ \\
\hline Mean & 9.5 & 6.8 & 8.9 & 4.3 & 10.2 & 6.0 & 10.1 & 9.3 \\
Median & 8.0 & 4.9 & 6.7 & 1.9 & 8.3 & 3.7 & 7.8 & 7.1 \\
Standar Deviasi & 3.1 & 3.6 & 3.8 & 3.5 & 2.2 & 3.2 & 3.8 & 3.3 \\
Minimum & 3 & 2 & 2 & 0 & 6 & 0 & 5 & 5 \\
Maksimum & 11 & 11 & 12 & 10 & 7 & 11 & 10 & 10 \\
Kurtosis & -.1 & -1. & -.4 & 1.6 & -1.0 & .41 & -1.5 & -.9 \\
\hline
\end{tabular}

Keterangan: $\mathrm{E}=$ Kelas eksperimen, $\mathrm{K}=$ Kelas kontrol.

Tabel 9. Uji ANOVA PKM Kelas Eksperimen dan Kontrol, Ditinjau dari GBM

\begin{tabular}{llllll}
\hline & Jumlah Kuadrat & Derajat kebebasan & Kuadrat tengah & F hitung & Sig. \\
\hline Between Groups & 377.734 & 7 & 53.962 & 4.645 & .000 \\
Within Groups & 1103.703 & 95 & 11.618 & & \\
Total & 1481.437 & 102 & & & \\
\hline
\end{tabular}


Hasil uji ANOVA menghasilkan p-value kurang dari 0,05 , ini artinya minimal ada dua rerata yang berbeda. Perbedaan itu lebih ditentukan oleh perbedaan antar kelas eksperimen dan kontrol bukan karena pengelompokkan GBM, hal itu di tandai dengan jumlah kuadrat dari within groups (dalam kelompok) lebih besar dari Between Groups (antar kelompok).

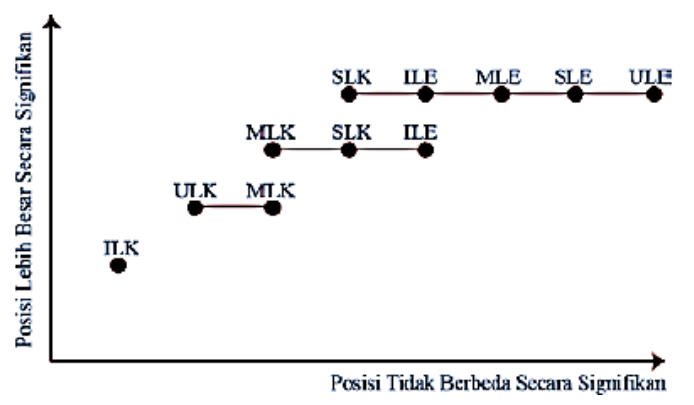

Gambar 4. Diagram Post Hoc PKM Kelas

Eksperimen dan Kontrol, Ditinjau dari GBM

Simpulan dari gambar tersebut, yaitu: (1) PKM siswa SLE dengan SLK tidak terdapat perbedaan secara signifikan, (2) PKM siswa MLE lebih besar dari MLK secara signifikan, (3) PKM siswa ULE lebih besar dari ULK secara signifikan, dan (4) PKM siswa ILE lebih besar dari ILK secara signifikan. Dari empat simpulan tersebut, temuan yang tidak sesuai hipotesis penelitian adalah PKM siswa SLE dengan SLK tidak terdapat perbedaan secara signifikan.

Sebagaimana KAM, hasil uji ANOVA memperlihatkan bahwa perbedaan GBM tidak menjadi faktor penentu perbedaan PKM siswa. Hal ini memberikan gambaran bahwa perlakuan pembelajaran sudah berlaku adil terhadap siswa dilihat dari sisi GBM siswa. Kondisi ini juga menjadi kabar baik karena National Council of Teachers of Mathematics (2000) mengajurkan pembelajaran matematika di kelas harus menciptakan rasa berkeadilan, dalam hal ini dilihat dari sisi GBM. Hasil perbandingan pengaruh pembelajaran terhadap kemampuan PKM dilihat dari faktor GBM memperlihatkan empat temuan yang perlu dibahas.

Pertama, PKM siswa kelas eksperimen tidak berbeda secara signifikan pada siswa GBM SL. Kondisi ini memunculkan pertanyaan, yaitu ada apa dengan GBM SL? Pertanyaan itu terjadi karena siswa GBM siswa selain SL pada kelas eksperimen memiliki PKM lebih besar secara signifikan dari kelas kontrol. Kalau melihat karakteristik siswa dengan GBM SL, yaitu: siswa dengan gaya belajar ini cenderung mandiri dan kreatif serta mempunyai kesiapan pengetahuan untuk mencapai kompetensi yang diharapkan (Strong et al., 2004) maka besar dugaan bahwa pencapaian PKM dengan perhatian dan tanpa perhatian khusus pada siswa dengan GBM ini akan mempunyai pengaruh pembelajaran yang relatif sama karena siswa GBM SL cenderung mandiri. Sementara itu, kemadirian yang tinggi berpengaruh pada kemampuan penyelesaian masalah matematika yang baik (Hadad, 2014). Akibat dari itu, tidak heran bila kemudian PKM siswa SLK tidak berbeda secara signifikan dengan GBM lain pada kelas eksperimen, khususnya dengan siswa SLE.

Kedua, PKM siswa GBM ML pada kelas eksperimen lebih besar daripada kelas kontrol. Hal ini merupakan hal yang menggembirakan. Kegembiraan ini dilatarbelakangi oleh fakta bahwa pembelajaran tidak dirancang secara terstruktur secara bertahap dan terbimbing maka siswa GBM ML akan kesulitan mengikuti pembelajaran (Strong et al., 2004). Hal ini menandakan bahwa RMT telah menyelenggarakan pembelajaran yang terstruktur secara bertahap dan membimbing serta memantau perkembangan PKM siswa.

Ketiga, PKM siswa GBM IL pada kelas eksperimen lebih besar daripada kelas kontrol. Temuan bahwa PKM siswa ILK jauh di bawah ILE cukup beralasan. Alasan pertama, siswa dengan GBM Interpersonal Learning (IL) cenderung belajar melalui percakapan, hubungan pribadi, dan kelompok (Strong et al., 2004), bila lingkungan di sekitar mereka tidak cukup memberikan ruang untuk memahami materi melalui iteraksi dengan rekan dan guru maka pencapaian kompetensi yang dicapai tidak akan optimal (Alifiani, 2017, p. 17; Sutawidjaja \& Dahlan, 2011, p. 4.18). Alasan kedua, pembelajaran pendekatan langsung yang tidak menuntut guru untuk mengaitkan pembelajaran konsep matematika yang pragmatis dan konkrit membuat siswa cenderung tidak cukup bergairah untuk belajar yang tentunya hal ini dapat berakibat langsung pada pencapaian kompetensi pula. Sementara itu, siswa ILE mendapat perlakuan sebaliknya sehingga hal ini menjadikan mereka mempunyai kompetensi PKM lebih baik dibanding siswa ILK.

Keempat, PKM siswa GBM UL pada kelas eksperimen lebih besar daripada kelas kontrol. Satu dari karekteristik dari pendekatan pembelajaran RMT adalah peka dengan pola dan selalu memberikan alasan-alasan mengapa sesuatu itu bisa terjadi atau terbentuk (Kinard \& 
Kozulin, 2008), sementara itu siswa GBM UL sangat menyukai karakteristik belajar seperti ini. Sebagai contoh, bagaimana operasi pengurangan oleh bilangan negatif menjadi ekivalen dengan penjumlahan melalui penjelasan pola operasi bilangan. Selain dari itu, penggunan alat psikologis gambar adalah alasan lain yang membuat siswa GBM UL menjadi lebih besar karena mereka melihat bahwa apa yang dilakukan sesuai dengan realitas (Strong et al., 2004).

\section{SIMPULAN}

Kemampuan PKM siswa pada pembelajaran pendekatan RMT lebih besar dari pembelajaran pendekatan langsung. Dilihat dari faktor gender menghasilkan simpulan bahwa PKM siswa wanita kelas eksperimen lebih besar secara signifikan dari kelas kontrol, akan tetapi pada kelas pria tidak berbeda secara signifikan.

Dilihat dari faktor KAM menghasilkan simpulan bahwa PKM siswa KAM sedang dan rendah pada kelas eksperimen lebih besar secara signifikan, akan tetapi pada siswa KAM tinggi tidak berbeda secara signifikan. Dilihat dari faktor GBM menghasilkan simpulan bahwa PKM siswa GBM ML, UL, dan IL pada kelas eksperimen lebih besar secara signifikan, akan tetapi pada siswa GBM SL tidak berbeda secara signifikan.

Pengaruh langsung dan tidak langsung dari komponen-komponen PKM pada kelas eksperimen maupun kontrol mempunyai jalur yang sama, yaitu: pemahaman konsep berpengaruh langsung terhadap pengoperasian konsep dan pengoperasian konsep mempunyai pengaruh langsung terhadap perelasian konsep, dari hal tersebut sehingga kemudian ada pengaruh tidak langsung pemahaman konsep terhadap perelasian konsep.

\section{DAFTAR PUSTAKA}

Abrams, P. (2013). Learning style inventory for students: Statistical analysis. Retrieved from

http://www.thoughtfulclassroom.com/lsis _research_report.pdf

Alifiani, A. (2017). Penerapan model pembelajaran NHT-TGT untuk meningkatkan motivasi dan pemahaman konsep materi matematika SMA. Jurnal Riset Pendidikan Matematika, 4(1), 11. https://doi.org/10.21831/jrpm.v4i1.13100

Arikunto, S. (1999). Dasar-dasar evaluasi pendidikan. Jakarta: Bumi Aksara.
Falik, L. (2007). An interview with Reuven Feuerstein. Journal of Cognitive Education and Psychology, 6(2), 272280.

https://doi.org/10.1891/194589507787382 223

Fennema, E. (1996). Mathematics, gender, and research. In Towards Gender Equity in Mathematics Education (pp. 9-26). Dordrecht: Kluwer Academic Publishers. https://doi.org/10.1007/0-306-47205-8_2

Feuerstein, R. (2000). Mediated learning experience, instrumental enrichment, and the learning propensity assessment device. In ICDL Clinical Practice Guidelines (pp. 557-577). Jerusalem: The Interdisciplinary Council on developmental and Learning Disorders, Bethesda. Retrieved from http://www.educationalsupport.com.au/Sit e_Data/Documents/mle.pdf

Feuerstein, R. (2017). Conductive education and structural cognitive modifiability.

Fitriyani, H. (2013). Profil berpikir matematis rigor siswa SMP dalam memecahkan masalah matematika ditinjau dari perbedaan kemampuan matematika. AdMathEdu: Jurnal Ilmiah Pendidikan Matematika, Ilmu Matematika Dan Matematika Terapan, 3(1). Retrieved from

http://journal.uad.ac.id/index.php/AdMath Edu/article/view/4831

Fraenkel, J. R., Wallen, N. E., \& Hyun, H. H. (2012). How to design and evaluate research in education. Singapore: McGraw-Hill Humanities/Social Sciences/Languages.

Golden, G. (2010). Mathematical learning inventory. Retrieved December 19, 2017, from

http://mathhombre.blogspot.co.id/2010/10 /mathematical-learning-inventory.html

Guiso, L., Monte, F., Sapienza, P., \& Zingales, L. (2008). Culture, gender, and math. Science, 320(5880), 1164-1165. https://doi.org/10.1126/science.1154094

Hassaskhah, J. (2012). Feuerstein's theory of mediation and its impact on EFL teachers' sense of efficacy. Journal of English Language Teaching Learning, 3(7), 89113. Retrieved from http://elt.tabrizu.ac.ir/article_621.html 
Hudojo, H. (2005). Pengembangan kurikulum dan pembelajaran matematika. Malang: Universitas Negeri Malang.

Isnarto, I., Wahyudin, W., Suryadi, D., \& Dahlan, J. A. (2014). Students' proof ability: Exploratory studies of abstract algebra course. International Journal of Education and Research, 2(6), 215-228. Retrieved

from http://www.ijern.com/journal/June2014/18.pdf

Khabib, J., \& Manoy, J. T. (2014). Pengembangan perangkat pembelajaran denganpendekatan RMT ditinjau dari fungsi kognitif siswa pada materi melukis segitiga di kelas VII SMP. MATHEdunesa, 3(2). Retrieved from http://jurnalmahasiswa.unesa.ac.id/index. php/mathedunesa/issue/view/709

Kilpatrick, J., Swafford, J., \& Findell, B. (2001). Adding it up. Washington, DC: National Academy Press.

Kinard, J., \& Kozulin, A. (2008). Rigorous mathematical thinking. Cambridge, MA: Cambridge University Press.

National Council of Teachers of Mathematics. (2000). Principles and standards for school mathematics. Reston. VA: National Council of Teachers of Mathematics.

National Research Council. (2002). Helping children learn mathematics. Washington, D.C.: National Academies Press. https://doi.org/10.17226/10434

OECD. (2010). PISA 2009 results: What students know and can do: Student performance in reading, mathematics and science (volume I). Retrieved from https://www.oecd.org/pisa/pisaproducts/4 8852548.pdf

Orton, A. (2004). Learning mathematics: Issues, theory, and classroom practice. New York, NY.: Continuum. Retrieved from https://books.google.co.id/books/about/Le arning_Mathematics.html?id=Fxp0eSHpS -IC\&redir_esc $=\mathrm{y}$

Paas, F., Merrienboer, J. Van, \& Gog, T. Van. (2011). Designing instruction for the contemporary learning landscape. In K. R. Harris, S. Graham, \& T. Urdan (Eds.), APA Educational Psychology Handbook: Vol. 3. Application to Learning and Teaching (pp. 335-357). Washington
D.C.: American Psychological Association. Retrieved from http://ro.uow.edu.au/edupapers/374

Presiden Republik Indonesia. Undang-Undang Republik Indonesia nomor 2 tahun 1989 tentang sistem pendidikan nasional, Pub. L. No. 2, Undang-Undang Republik Indonesia (1989). Retrieved from http://www.dpr.go.id/dokjdih/document/u $\mathrm{u} / 591 . p d f$

Pritchard, A. (2013). Ways of learning: Learning theories and learning styles in the classroom. New York, NY.: Routledge.

Pujiastuti, H., Kusumah, Y. S., Sumarmo, U., \& Dahlan, J. A. (2014). Inquiry co-operation model for enhancing junior high school student's mathematical problem solving ability. International Journal of Contemporary Educational Research, l(1), 51-60.

Reys, R. E., Lindquist, M. M., Lambdin, D. V., \& Smith, N. L. (2014). Helping children learn mathematics. New York, NY.: Wiley.

Samparadja, H., Suryadi, D., \& Kartasasmita, B. G. (2014). The Influence of inductivedeductive approach based on modified definition in algebra structure learning toward student's proving ability viewed based on college entrance track. International Journal of Education and Research, 2(7), 239-248. Retrieved from http://www.ijern.com/journal/July2014/20.pdf

Sari, D. P., Nurochmah, N., Haryadi, H., \& Syaiturjim, S. (2016). Meningkatkan kemampuan pemahaman matematis melalui pendekatan pembelajaran student teams achivement division. Jurnal Riset Pendidikan Matematika, 3(1), 16. https://doi.org/10.21831/jrpm.v3i1.7547

Schoenfeld, A. H. (1983). Problem solving in the mathematics curriculum: A report, recommendations, and an annotated bibliography. Washington D.C.: Mathematical Association of America, Committee on the Teaching of Undergraduate Mathematics.

Strong, R., Thomas, E., Perini, M., \& Silver, H. (2004). Creating a differentiated mathematics classroom. Improving Achievement in Math and Science, 61(5), 


\section{Jurnal Riset Pendidikan Matematika, 4 (2), 2017 - 199}

Aan Hendrayana

$73-78$.

Retrieved

from

http://www.ascd.org/publications/educatio

nal-

leadership/feb04/vol61/num05/Creating-

a-Differentiated-Mathematics-

Classroom.aspx

Susilo, F. (2004). Matematika humanistik. Yogyakarta: Basis.

Sutawidjaja, A., \& Dahlan, J. A. (2011). Model pembelajaran langsung. In A. Sutawidjaja \& J. A. Dahlan (Eds.), Pembelajaran Matematika. Jakarta: Universitas Terbuka.

Sweller, J. (1988). Cognitive load during problem solving: Effects on learning. Cognitive Science, 12(2), 257-285. https://doi.org/10.1207/s15516709 $\operatorname{cog} 120$ 24

Sweller, J. (1994). Cognitive load theory, learning difficulty, and instructional design. Learning and Instruction, 4(4), 295-312. https://doi.org/10.1016/09594752(94)90003-5

Sweller, J., Ayres, P., \& Kalyuga, S. (2011). Cognitive load theory. New York, N.Y.:
Springer.

Syamsuri, S., Purwanto, P., Subanji, S., \& Irawati, S. (2016). Characterization of students formal-proof construction in mathematics learning. Communications in Science and Technology, 1(2), 42-50. https://doi.org/10.21924/cst.1.2.2016.2

Tan, O. S. (2003). Problem-based learning innovation: using problems to power learning in the 21st century. Singapore: Cengage Learning Asia.

Vygotsky, L. S. (1978). Mind in society: The development of higher psychological processes. Mind in Society The Development of Higher Psychological Processes, Mind in So, 159. https://doi.org/10.1007/978-3-540-927846

Zubaidah, A. Y. (2012). Identifikasi kemampuan berpikir matematis rigor siswa sekolah dasar ditinjau dari aspek kemampuan matematika dalam memecahkan masalah matematika pokok bahasan pecahan. UIN Sunan Ampel Surabaya. Retrieved from http://digilib.uinsby.ac.id/9637/ 